\title{
Active and Reactive Power Control of ESS in Distribution System for Improvement of Power Smoothing Control
}

\author{
Seong-Su Shin*, Joon-Seok Oh**, Su-Hyeong Jang***, Jae-Hun Cha ${ }^{\S}$ \\ and Jae-Eon Kim ${ }^{\dagger}$
}

\begin{abstract}
This paper proposes a new control technique of energy storage system (ESS) for smoothing the active power of renewable energy sources (RES) such as photovoltaic and wind turbine generation. As the penetration of RES into grid increases, it is difficult to maintain the permissible level of power quality, that is, voltage and frequency fluctuation in power systems. To solve this problem, ESS control methods using low pass filter (LPF) have been proposed for mitigating the fluctuation of RES output. However, those have a lot of drawbacks which need to be supplemented. Hence, this paper presents the improved active power control with additional reactive power control for maintaining power quality properly. The proposed method minimizes the capacity of ESS to be required for smoothing RES output fluctuation through mitigation of phase delay problem in LPF. In addition, the voltage regulation improves by using additional reactive power control. The proposed method was verified through simulation analysis using PSCAD/EMTDC.
\end{abstract}

Keywords: Renewable energy sources, Energy storage system, Power smoothing control

\section{Introduction}

Thanks to the advancement of renewable energy technique such as power electronics and electrical materials, the RESs have been commercialized successfully. As the operating costs of RESs are continually diminishing, the penetration rate of RES is dramatically increasing [1]. Especially, after RESs are adopted as distributed generation (DG) to substitute for synchronous generator which has conventional grid inertia, energy supply structures are also changed to inverter-based power conditioning systems (PCS) [2].

However, this change has serious impact on the conventional power systems and transmission lines designed for constant frequency due to the weak inertia of grid caused by the PCS. Also, RESs have in common the intermittent characteristic which is influenced by environmental factor such as instantaneous changes of weather. Eventually it causes voltage and frequency fluctuations [3, 4]. From the point of view of system operator, these cases become harder to maintain the permissible level of power quality in distribution systems. One solution for such a problem is the application of ESS which can implement power smoothing control and many studies and experiments are currently underway [5].

$\dagger \quad$ Corresponding Author: School of Electric Engineering, Chungbuk National University, Korea. (jekim@chungbuk.ac.kr)

* Korea Electric Association. (shins@elec.or.kr)

** Korea Electric Power Corporation. (jsoh@kepco.co.kr)

*** LS industrial System Corporation, Korea. (suhjang@lsis.com)

$\S \quad$ School of Electric Engineering, Chungbuk National University, Korea.(01055849970@naver.com)

Received: June 27, 2016; Accepted: February 1, 2017
ESS has been used for various purposes like electric supply reserve capacity, time-of-use based electricity demand response, and uninterrupted power supply [6]. The most powerful advantage of ESS is to flexibly control active and reactive power simultaneously. Hence, ESS can be applied to grid-supporting operation such as load leveling, power smoothing control, and voltage regulation. Coordination operation of distributed generation in voltage/reactive power control is on an upward tendency. Among them, power smoothing control by ESS is one of the methods for mitigating active power fluctuation of RESs. In this case, it is important to decide the output reference of ESS related to its capacity. In general, weather forecasting [7] and signal processing by LPF [8] have been proposed for calculating the output reference of ESS.

These methods have some problems. First, it incurs the excessive ESS capacity caused by inaccurate reference. The output prediction through weather forecasting cannot get reliable data perfectly and the LPF method generates excessive damping or phase delay. That is to say, these methods result in unnecessary ESS capacity. For solving this issue, active power control should be simultaneously implemented with reactive power within the kVA or MVA rate capacity of ESS. Because operators should decide the rate of reactive power to real power in respect of benefits or incomes. Second, power smoothing control using active power only has little effect on the mitigation of voltage fluctuation in distribution system. Therefore, ESS should properly control the active power as well as reactive power for better performance of power quality maintenance [9].

In this paper, a new improved power control method of ESS is proposed, which is to minimize the active power 
reference error simultaneously with the reactive power control. The frequency response characteristic of proposed controller is designed by MATLAB. In addition, the proposed method is verified through modeling and simulating the model power system with RES and ESS by PSCAD/ EMTDC software package. The comparisons between conventional method and proposed method are also carried out by same process for power smoothing.

\section{Control Structure of Power Smoothing Control}

Fig. 1 shows the power system with DG combined of RES and ESS. RES and ESS operate as a grid-feeding power converter which generates a desired active and reactive power [10]. Their converters implement PLL for synchronization with power system. In Fig. 1, the phase of power system is considered as zero and the one of RES and ESS is $\delta$. In addition, the controller of grid-feeding power converter consists of outer power control loop and inner current control loop as shown in Fig. 2. Therefore, RES and ESS can be considered as current sources with high parallel output impedance. Assuming that RES implements a MPPT, the complex power injected to power system is in the following as:

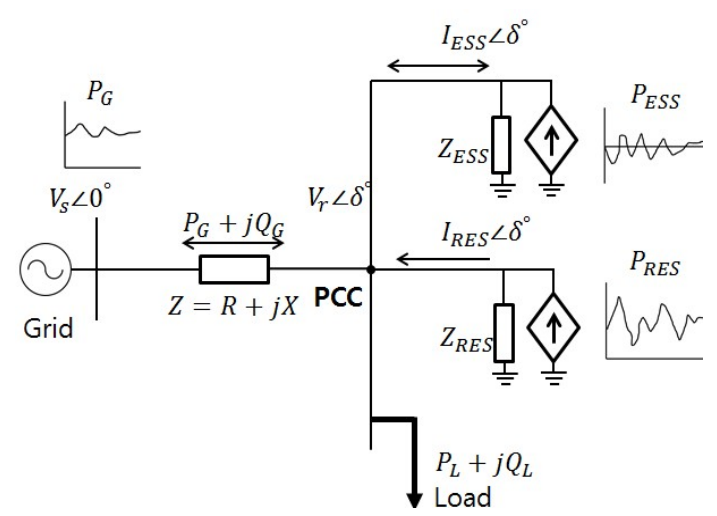

Fig. 1. System configuration with RES and ESS for power smoothing

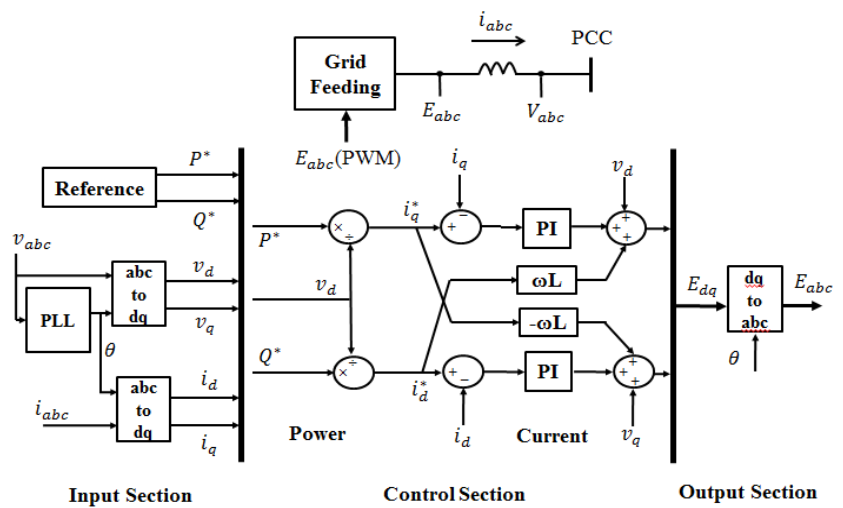

Fig. 2. Control structure of grid-feeding power converter

$$
S=V I^{*}=\mathrm{V}_{\mathrm{PCC}} \angle \delta^{\circ}\left\{\left(I_{E S S}+I_{R E S}\right) \angle\left(-\delta^{\circ}\right)\right\} \approx P_{\text {Smooth }}^{*}
$$

For accurate control of ESS for power smoothing, it is necessary to calculate a reference of active power correctly. Fig. 3 shows the control structure of ESS for power smoothing control. Many papers prefer the method using LPF because it is easy to set up the control structure. In this control structure, the section of determining the output reference value of ESS is the subtraction of the active power signal of RES from the signal passing through the LPF. The transfer function of LPF and active power reference of ESS can be written as:

$$
\begin{aligned}
P_{R E S_{S m}}(s) & =\left\{\frac{\omega_{n}^{2}}{s^{2}+2 \zeta \omega_{n} s+\omega_{n}^{2}}\right\} P_{R E S}(s) \\
P_{E S S}^{*} & =P_{R E S_{-} s m}-P_{R E S}
\end{aligned}
$$

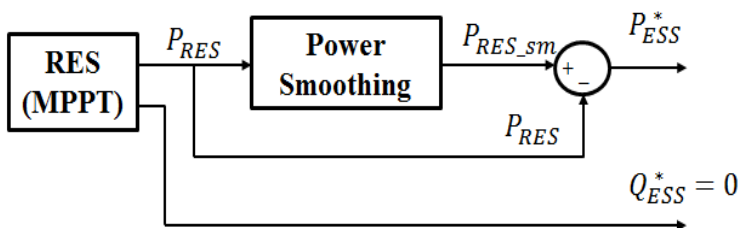

Fig. 3. Control structure of ESS for power smoothing
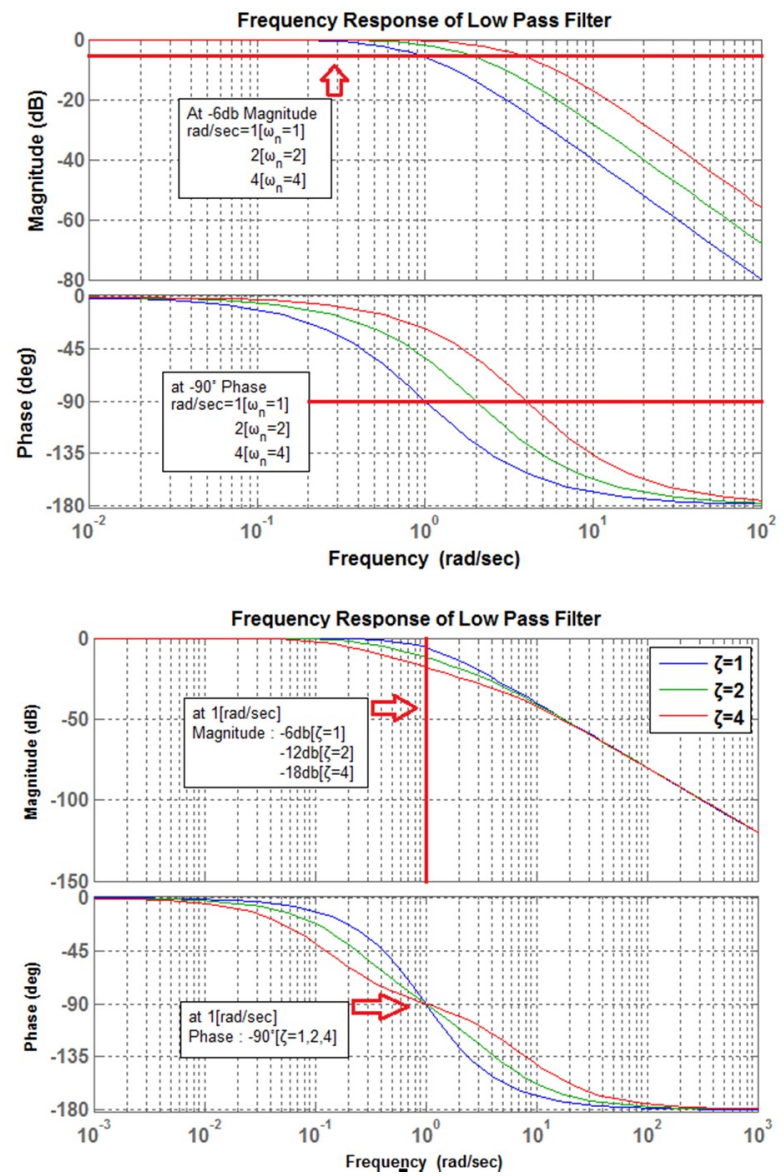

Fig. 4. Frequency response of second order LPF 
Where the $\zeta$ is damping ratio and the $\omega_{n}$ is natural undamped frequency. Also, the reactive power reference value of ESS is zero because RES does not generate a reactive power through MPPT. The level of smoothing effect depends on the above mentioned parameters. Therefore, it is very important to adjust the parameters which suit the occasions.

\section{Drawbacks to Conventional Power Smoothing Control using LPF}

The core of conventional power smoothing technique is the use of LPF to smoothen the signal of active power of RES. However, even though this method can make the signal of output power enough to smooth, several drawbacks exist as well. Fig. 4 shows the frequency response of second order LPF in which $\zeta$ and $\omega_{n}$ are set to 1 respectively like blue lines of bode plots. It is obvious that the greater the natural undamped frequency is, the greater the effect of damping is. This response signifies that the signal might be an overdamped signal such as nearly constant value due to inadequate setting parameter. It leads to an unnecessary operation of ESS. Though this operation of ESS can perfectly reduce an output fluctuation of RES, the State-Of -Charging (SOC) and Discharging (SOD) of ESS are also excessively fluctuating. In this case, it will be more difficult for operators to maintain ESS so that this situation should be avoided.

Let us assume that the parameter of LPF is properly determined. Nevertheless, it is inevitable that the signal has a phase delay in accordance with frequency response of LPF [11]. The phase delay of LPF is 90 degree at cutoff frequency as bold red line in Fig. 4. On the other hand, the damping effect is diminished if the frequency is adjusted lower to lessen the phase delay. On the contrary, phase delay will be increased if cutoff frequency is increased as depicted in Fig. 4 from blue line to red line. It means that the method using LPF will continue to have a tradeoff between phase delay and power smoothing effect. Fig. 5 shows the two drawbacks focusing on the LPF. Consequently, the ideal method is the use of system in which has no phase delay enough to smoothen the signal and many papers are concentrated on this problems $[12,13]$.

The purpose of ESS for power smoothing control of RES is the enhancement of power quality to stabilize the voltage and frequency. However, a lot of the conventional power smoothing techniques is only focusing on the active power. For better performance of power quality improvement, the control of reactive power is necessary [14]. By the relation between voltage and reactive power Fig. 6, voltage regulation should be controlled using the reactive power within the tolerance range of power factor and capacity. Although the reactive power supply like static var compensator (SVC) is installed in power system, it is

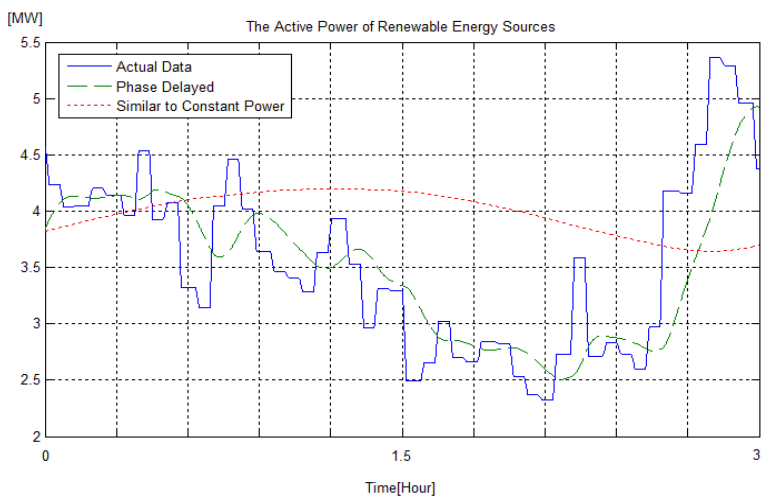

Fig. 5. Two cases of LPF(over-damped, phase delayed)

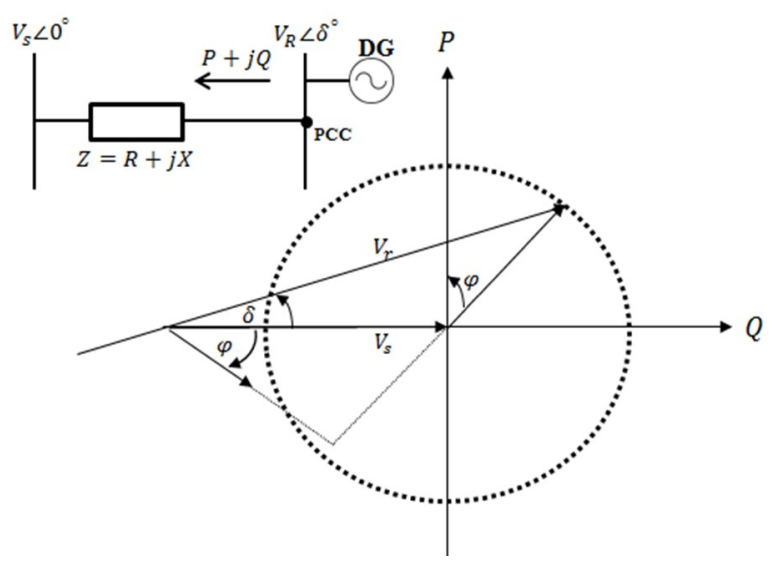

Fig. 6. Influence of active and reactive power injection by RES

hard to adjust the heavy fluctuation of voltage caused by RES. In this circumstance, ESS can be an alternative by injecting or absorbing reactive power according to the voltage fluctuation of PCC.

\section{Proposed Power Control Method of ESS for Power Smoothing Control}

Through the previous section, requirements for improvement of ESS for power smoothing in order to mitigate an effect by RES are as in the following: prevention of excessive compensation, minimization of the loss caused by phase delay, and addition of reactive power control. For satisfaction of requirements, this paper proposes the power control method of ESS like Fig. 7.

In case of active power, Band Pass Filter (BPF) and Band Reject Filter (BRF) are substituted for LPF. This combination is similar to notch filter. The role of BRF is signal smoothing with minimizing phase delay by adjusting parameter A. Additionally, BPF is designed to adjust the amplitude of signal. For the flexible operation of ESS for power smoothing control, the parameter A and B can be adjusted according to SOC or SOD of ESS. The frequency 


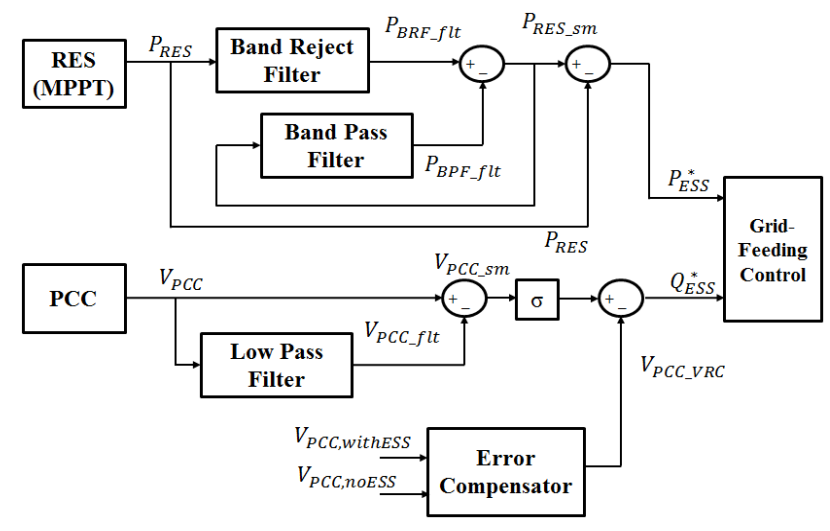

Fig. 7. Proposed power control method of ESS for improved power smoothing

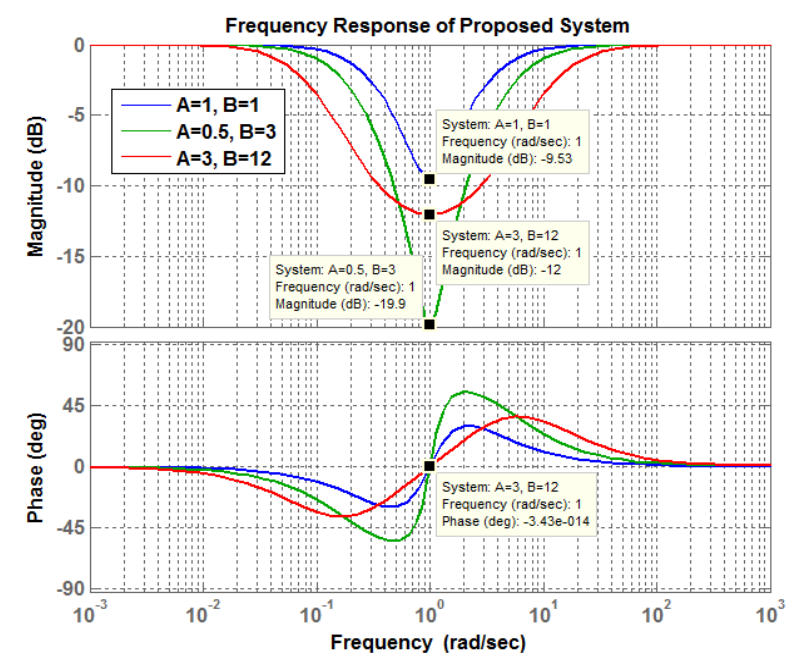

Fig. 8. Frequency response of active power control

response of active power control is as in the following Fig. 8. The relational expression of section in active power can be written as:

$$
\begin{aligned}
& P_{B R F_{-} f l t}(s)=\left\{\frac{s^{2}+A \omega_{n} s+\omega_{n}^{2}}{s^{2}+2 \zeta \omega_{n} s+\omega_{n}^{2}}\right\} P_{R E S}(s) \\
& P_{B P F_{-} f l t}(s)=\left\{\frac{B \omega_{n} s}{s^{2}+2 \zeta \omega_{n} s+\omega_{n}^{2}}\right\} P_{R E S_{-} s m}(s) \\
& G(s)=\frac{P_{R E S_{-} s m}(s)}{P_{R E S}(s)}=\frac{s^{2}+A \omega_{n} s+\omega_{n}^{2}}{s^{2}+\left(2 \zeta+B \omega_{n}\right) s+\omega_{n}^{2}}
\end{aligned}
$$

In case of reactive power, the process of subtraction of the voltage signal at PCC passing through the LPF from original signal is added. Especially, the reason of using LPF in reactive power is the frequency component of voltage which is lower than frequency component of active power. Therefore, it is sufficient to smoothen the voltage regulation using LPF. In addition, the amplitude coefficient $\sigma$ is determined to adjust a magnitude of reactive power for level of voltage mitigation effect. Finally, excessive or

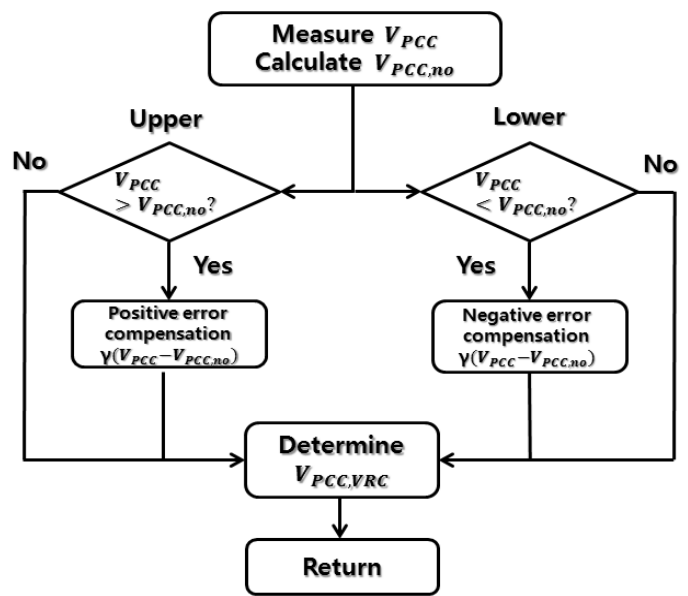

Fig. 9. The algorithm of voltage error compensator

insufficient compensation can be prevented by voltage error compensator which is making a comparison between voltage at PCC with and without ESS. The relational expression of section in reactive power can be expressed as follows:

$$
\begin{aligned}
& V_{P C C}^{*}(\mathrm{~s})=\left\{\frac{\omega_{n}^{2}}{s^{2}+2 \zeta \omega_{n} s+\omega_{n}^{2}}\right\} V_{P C C}(s) \\
& Q_{E S S}^{*}=\sigma\left(V_{P C C}-V_{P C C}^{*}\right)-V_{P C C_{V R C}} \\
& V_{P C C_{-} V R C}=\gamma\left(V_{P C C}-V_{P C C_{-} n o}\right)
\end{aligned}
$$

Fig. 9 shows the algorithm of voltage error compensator. The voltage at PCC without ESS $V_{P C C, n o}$ should be calculated by formulas of voltage regulation. Using this value, comparison between $V_{P C C}$ and $V_{P C C, n o}$ will be performed. When $V_{P C C}$ is bigger than $V_{P C C, n o}$, the positive error compensation is considered. In contrary, when $V_{P C C}$ is smaller than $V_{P C C, n o}$, the negative error compensation is considered. The level of compensation can also adjust by controlling $\gamma$.

\section{Simulation Result and Analysis}

For verification of proposed control method, the simulation is carried out using PSCAD/EMTDC. Fig. 10 shows the configuration of simulation and Table 1 shows the specification of configuration. For observation of voltage regulation caused by RESs, conventional voltage compensators like step voltage regulator or SVC are not considered. Therefore, the voltage at distribution will be displayed with heavy fluctuation. The comparative analysis between conventional and proposed method is performed in this section. In the simulation results, it will focus on the difference in performance of smoothing effect of RES, required capacity of ESS, and improvement of power quality like mitigation effect of voltage regulation. 
Table 1. Specification of power system for verification

\begin{tabular}{|c|c|c|}
\hline Index & Value & Remarks \\
\hline \multicolumn{3}{|c|}{ Power Grid } \\
\hline Rated Power & 100MVA & \\
\hline Rated Voltage & $154 \mathrm{kV}$ & \\
\hline Rated Frequency & $60 \mathrm{~Hz}$ & \\
\hline Exciter Reference & 1.05 p.u. & $154 \mathrm{kV}$ based \\
\hline Inertia Constant & $5.117 \mathrm{~s}$ & \\
\hline \multicolumn{3}{|c|}{ 3-Winding Transformer(154kV-22.9kV-6.6kV) } \\
\hline Rated Power & 45MVA & \\
\hline$\% X_{1-2}$ & $16.16 \%$ & \multirow{3}{*}{$\begin{array}{c}\text { 45MVA } \\
\text { based }\end{array}$} \\
\hline$\% X_{2-3}$ & $6.69 \%$ & \\
\hline$\% X_{3-1}$ & $25.38 \%$ & \\
\hline Type of Connection & $\mathrm{Y}-Y_{g}-\Delta$ & \\
\hline \multicolumn{3}{|c|}{ Transmission Line $(22.9 \mathrm{kV}, 16 \mathrm{~km})$} \\
\hline Total $\% R_{1}$ & $61.11 \%$ & \multirow{6}{*}{$\begin{array}{c}\text { 100MVA } \\
22.9 \mathrm{kV} \\
\text { based }\end{array}$} \\
\hline Total $\% X_{1}$ & $109.55 \%$ & \\
\hline Total $\% R_{0}$ & $152.41 \%$ & \\
\hline Total $\% X_{0}$ & $311.27 \%$ & \\
\hline Total Resistive Load & $12 \mathrm{MW}$ & \\
\hline Total Inductive Load & 6Mvar & \\
\hline \multicolumn{3}{|c|}{ Distributed Generation $(22.9 \mathrm{kV})$} \\
\hline Rated Power(RES) & $35 \mathrm{MW}$ & $\mathrm{PV}+\mathrm{WT}$ \\
\hline Rated Power(ESS) & 10MVA & \\
\hline $\begin{array}{l}\text { Transformer Type } \\
\text { of Connection }\end{array}$ & $Y_{g}-\Delta$ & \\
\hline$\% X_{1}$ & $20 \%$ & $\mathrm{DG}+\mathrm{TR}$ \\
\hline \multicolumn{3}{|c|}{ Power Control System(Filter) } \\
\hline$\omega_{n}$ & $\begin{array}{l}0.9 \mathrm{~Hz}(\mathrm{P}) \\
0.3 \mathrm{~Hz}(\mathrm{Q})\end{array}$ & \multirow{3}{*}{$\begin{array}{l}\text { 2-Order } \\
\text { Filter }\end{array}$} \\
\hline$\zeta$ & 1 & \\
\hline Gain & 1 & \\
\hline
\end{tabular}

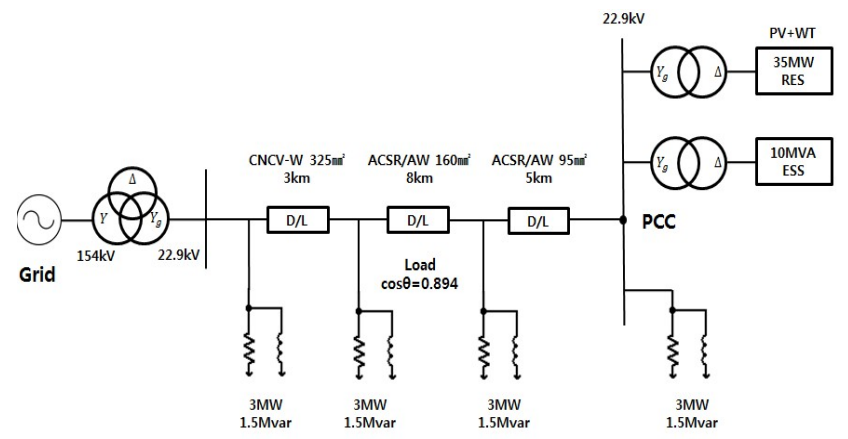

Fig. 10. Configuration of power system for verification

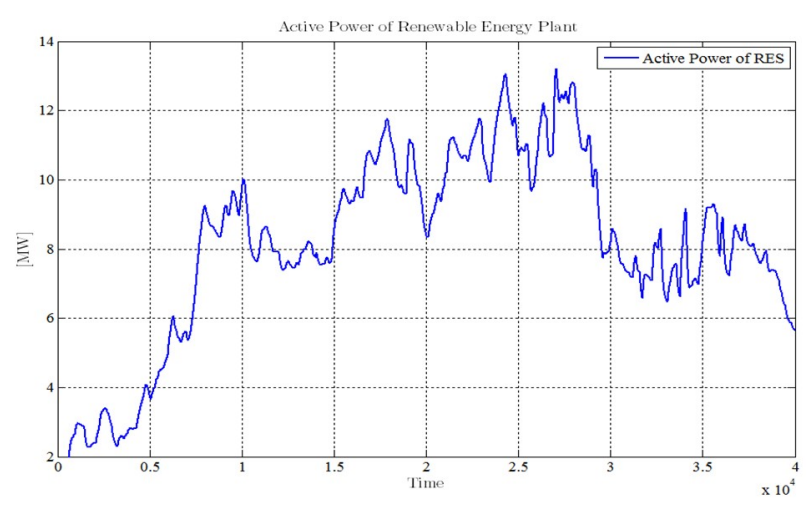

Fig. 11. Active power of renewable energy plant

\subsection{Power smoothing effect without phase delay}

Fig. 11 shows the active power of renewable energy plant based on wind generation and photovoltaic generation data. In case of wind generation, it is measured from wind turbine located in Samdal, Jeju in Korea. In case of photovoltaic generation, a generated data which has the output characteristics of PV is also added to the data of RES. The simulation is performed to compare the proposed method with LPF under same power smoothing effect. In case of conventional LPF, $\omega_{n}$ is set to $0.18 \mathrm{~Hz}$. To perform the two methods in same condition, B parameter of proposed method is set to 6 . Fig. 12 shows the comparison of smoothing effect between LPF and proposed method. The data of proposed method has not phase delay in comparison with data of LPF.

Because the phase delay is eliminated in proposed method, ESS needs the less required active power for power smoothing control in comparison with LPF. Fig. 13 shows the comparison of required active power between LPF and proposed method. The required active power of LPF is greater than proposed method at all the sections of

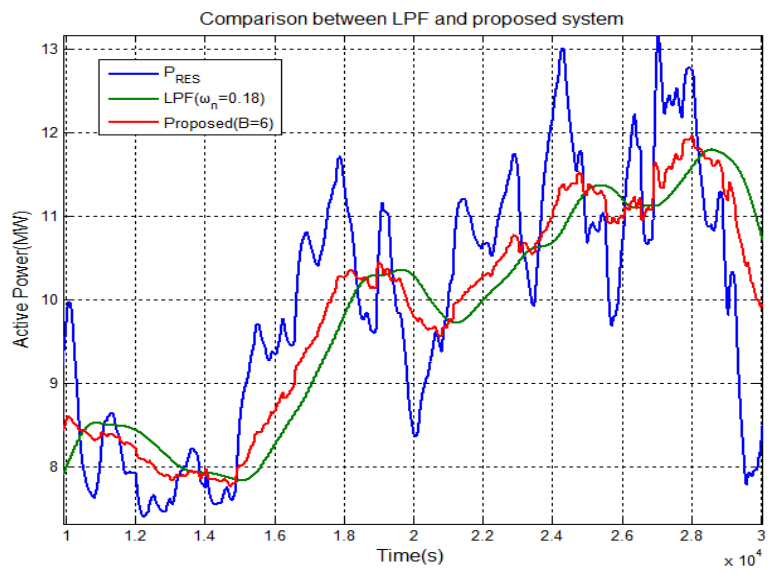

Fig. 12. Comparison of smoothing effect between LPF and proposed method

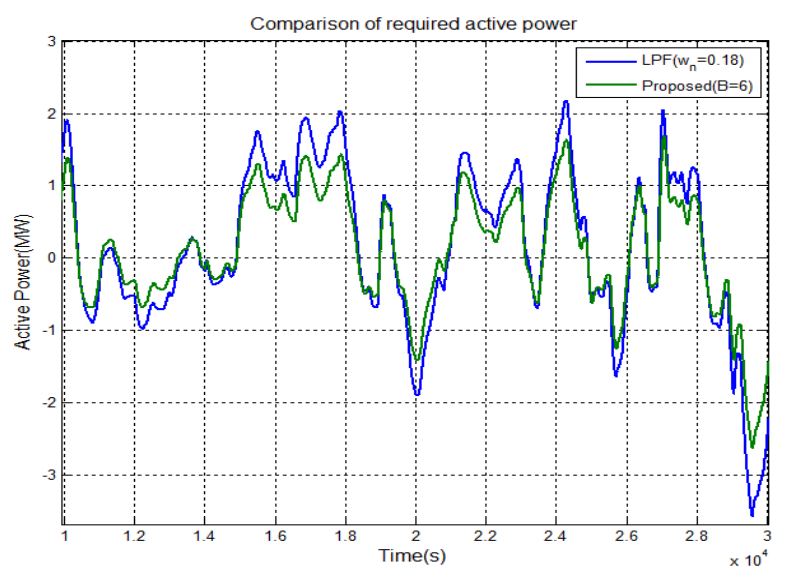

Fig. 13. Comparison of required active power between LPF and proposed method 
Fig. 13. Table 2 shows the specification of simulation results in Fig. 12 and Fig. 13.

Operators can control the level of smoothing effect by adjusting the parameter of BPF. Fig. 14 shows the comparison of power smoothing effect according to the change of parameter $\mathrm{B}$. The bigger the $\mathrm{B}$ is, the better performance of smoothing effect can be obtainable. The problem of unnecessary compensation previously mentioned can happen if the gain of BPF is too high. Therefore, operators should be discretion in controlling of gain parameter in case of insufficient SOC. In case of LPF, $\omega_{n}$

Table 2. Specification of simulation results in active power

\begin{tabular}{c|c|c|c}
\hline Index & $\begin{array}{c}\text { No Use } \\
\text { ESS }\end{array}$ & $\begin{array}{c}\text { Low Pass } \\
\text { Filter }\end{array}$ & $\begin{array}{c}\text { Proposed } \\
\text { System }\end{array}$ \\
\hline $\begin{array}{c}\text { Snapshot of } \\
\text { Simulation }\end{array}$ & \multicolumn{3}{|c}{$1.8 \mathrm{~s} \sim 2.2 \mathrm{~s}$} \\
\hline $\begin{array}{c}\text { Power } \\
\text { Fluctuations }\end{array}$ & $\begin{array}{c}8.4 \mathrm{MW} \\
\sim 11.75 \mathrm{MW}\end{array}$ & \multicolumn{2}{|c}{$9.6 \mathrm{MW} \sim 10.3 \mathrm{MW}$} \\
\hline Required Power & & $\begin{array}{l}-1.9 \mathrm{MW} \\
2.0 \mathrm{MW}\end{array}$ & $\begin{array}{c}-1.3 \mathrm{MW} \\
1.4 \mathrm{MW}\end{array}$ \\
\hline
\end{tabular}

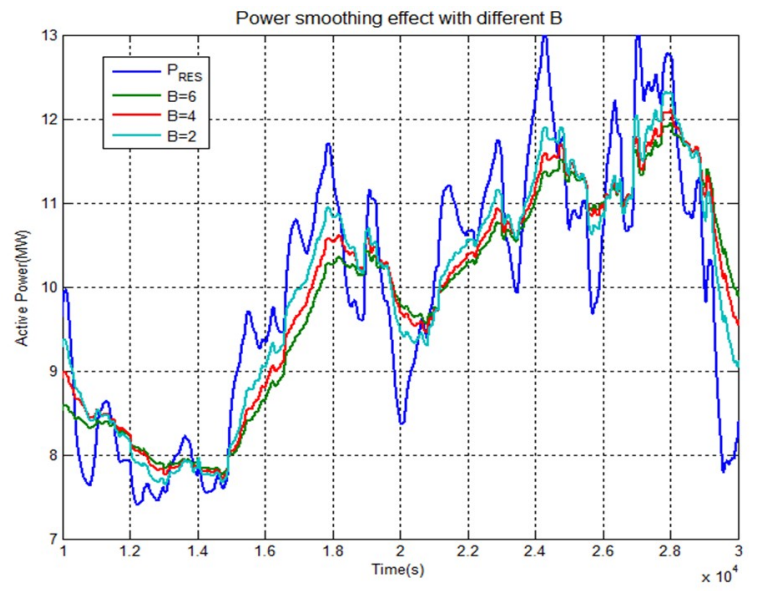

Fig. 14. Comparison of power smoothing effect according to the change of parameter B

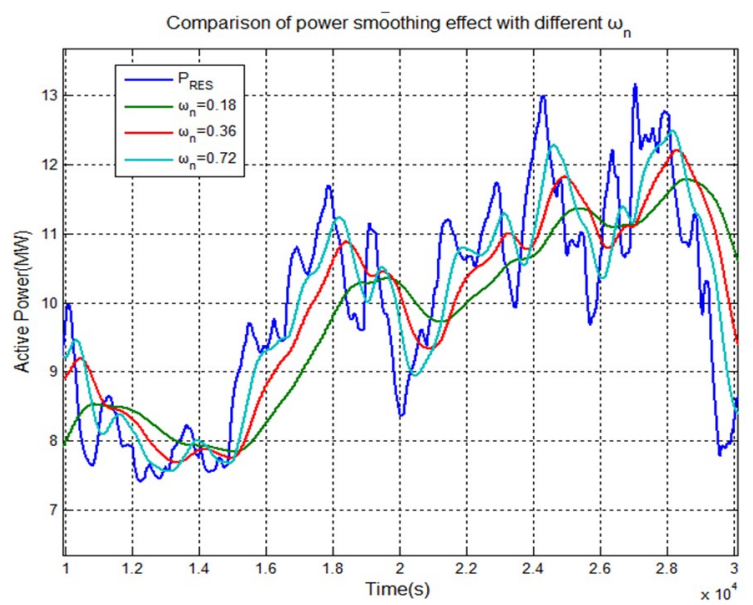

Fig. 15. Comparison of power smoothing effect according to the change of parameter $\omega_{n}$ should be adjusted for determination of power smoothing effect. However, the bigger the $\omega_{n}$ is, the worse phase delay happens according to the frequency response of LPF. Fig. 15 shows the comparison of power smoothing effect according to the change of $\omega_{n}$. For these reasons, proposed power control method has better performance than conventional LPF in case of required power of ESS.

\subsection{Improved voltage smoothing effect by controlling reactive power}

In the simulation of voltage at $\mathrm{PCC}$, three cases are considered: no use of ESS, use of ESS with P control, and use of ESS with $\mathrm{P}$ and $\mathrm{Q}$ control. Unlike previous simulation of active power, parameter B is set to 1 . Fig. 16 shows the voltage at $\mathrm{PCC}$ with and without reactive power control. The starting point of reactive power control is marked using arrow. Actually, voltage fluctuation is mitigated once any power smoothing techniques is used. However, comparing between the case of no use ESS and P

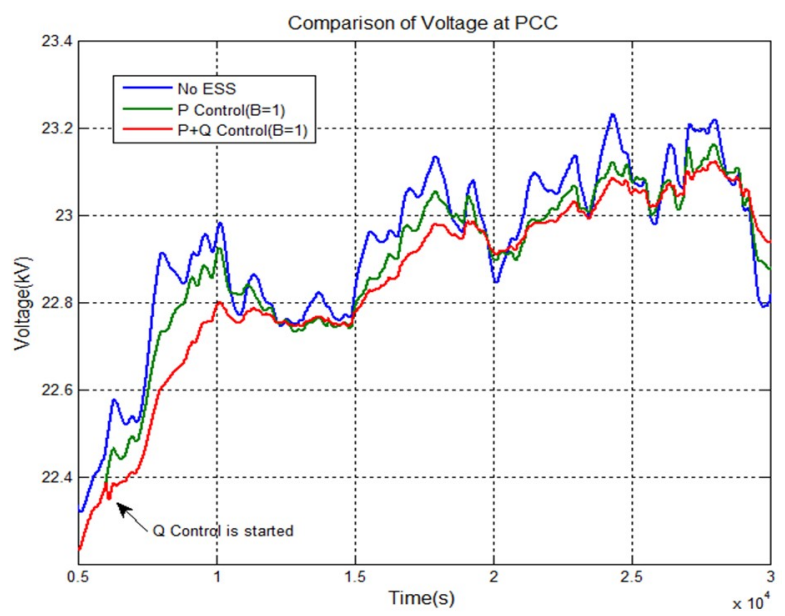

Fig. 16. Comparison of voltage at PCC between with and without Q control

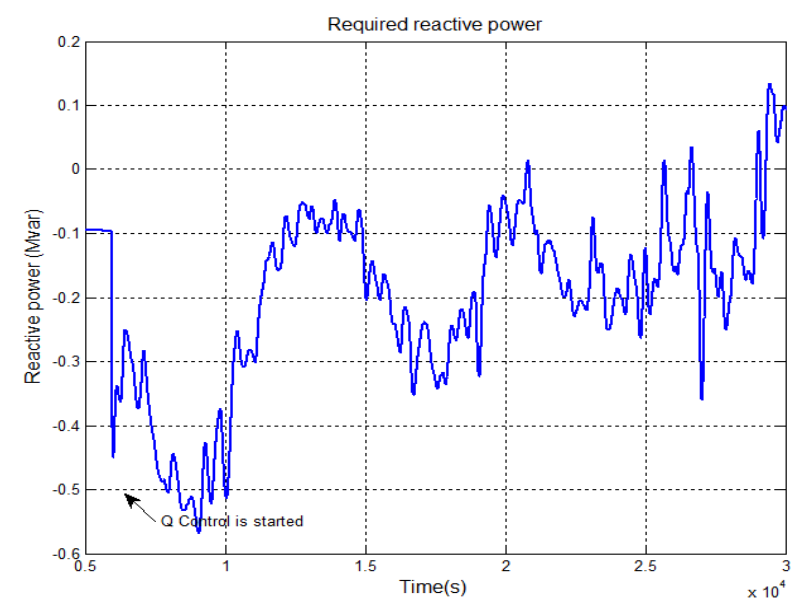

Fig. 17. Comparison of required reactive power according to the offset coefficient 
control without reactive power control, the effect of mitigation is not excellent. Through the additional reactive power control, it can help to mitigate voltage fluctuation effectively. Fig. 17 shows the required reactive power and Table 4 shows the specification of simulation results in Fig. 16 and Fig. 17.

The amplitude coefficient is determined to adjust the voltage mitigation effect. Fig. 18 shows the comparison of voltage at PCC according to the level of amplitude coefficient. The smaller the amplitude coefficient is, the lower the voltage mitigation effect is. Operators should be

Table 3. Specification of simulation results in PCC voltage

\begin{tabular}{c|c|c|c}
\hline Index & No Use ESS & $\begin{array}{c}\text { Without } \\
\text { Q control }\end{array}$ & $\begin{array}{c}\text { With } \\
\text { Q control }\end{array}$ \\
\hline $\begin{array}{c}\text { Snapshot of } \\
\text { Simulation }\end{array}$ & \multicolumn{3}{|c}{$1.8 \mathrm{~s} \sim 2.2 \mathrm{~s}$} \\
\hline $\begin{array}{c}\text { Voltage } \\
\text { Magnitude }\end{array}$ & $\begin{array}{c}23.13 \mathrm{kV} \\
\sim 22.85 \mathrm{kV}\end{array}$ & $\begin{array}{c}23.06 \mathrm{kV} \\
\sim 22.89 \mathrm{kV}\end{array}$ & $\begin{array}{c}22.97 \mathrm{kV} \\
\sim 22.91 \mathrm{kV}\end{array}$ \\
\hline Decrease in & - & $56.67 \%$ & $78.58 \%$ \\
Fluctuation & - & - & $\begin{array}{c}-0.3 \mathrm{Mvar} \\
\sim-0.2 \mathrm{Mvar}\end{array}$ \\
\hline Required Power & - & \multicolumn{2}{|c}{}
\end{tabular}

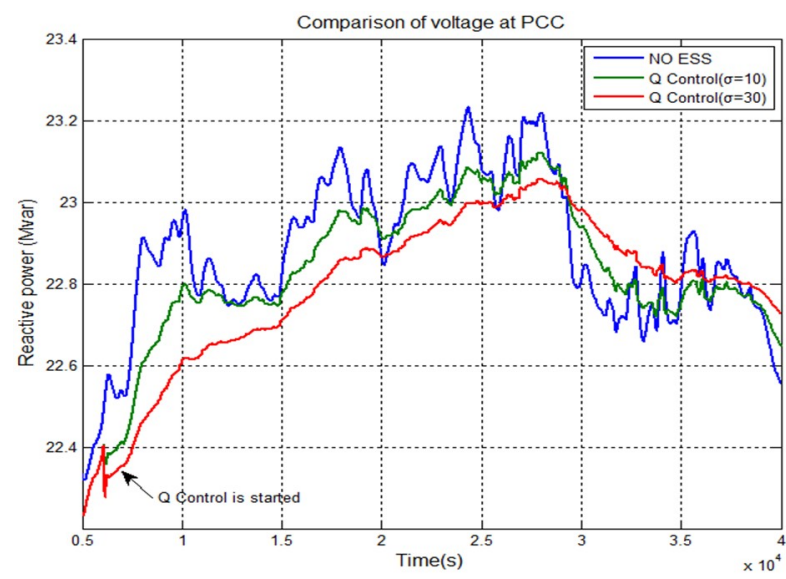

Fig. 18. Mitigation effect of voltage fluctuation according to the change of amplitude coefficient $\sigma$

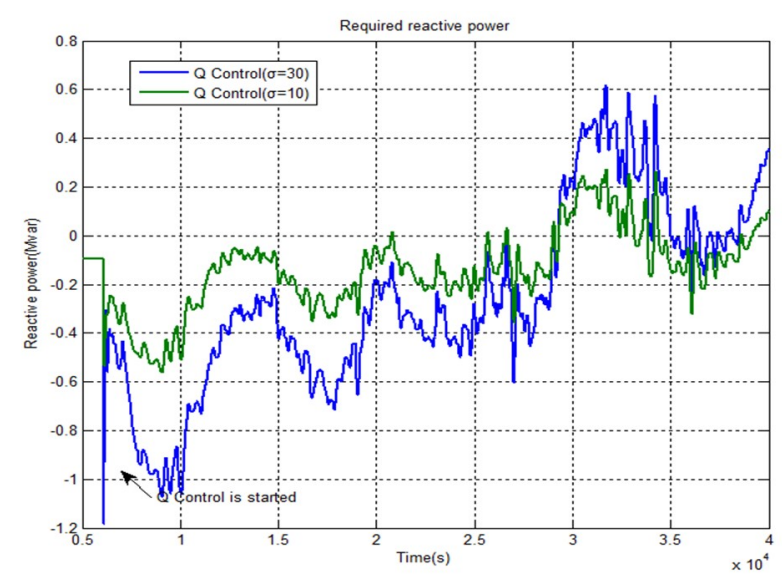

Fig. 19. Required reactive power according to the change of amplitude coefficient $\sigma$ discretion in controlling amplitude coefficient. Fig. 19 shows the required reactive power according to the level of amplitude coefficient.

The role of voltage error compensator is to prevent unnecessary or insufficient compensation of voltage regulation caused by LPF. Fig. 20 and 21 show the difference of with and without voltage error compensator. In case of non- $Q$ control, the magnitude of voltage is too high or too low in comparison with original situation. In worst case, it can cause an over-voltage in distribution system due to excessively required reactive power. Therefore, the voltage error compensator is necessary to regulate a voltage in distribution system. Operators can also adjust the control level of voltage magnitude by adjusting the offset coefficient. As the offset coefficient decreases, the magnitude of voltage is lower. However, the problems of voltage drop and voltage rise beyond the tolerance band $1 \pm 0.05$ p.u. also happen if the coefficient is significantly low. Therefore, operators should be discretion in controlling of offset coefficient as in the same case of active power control.

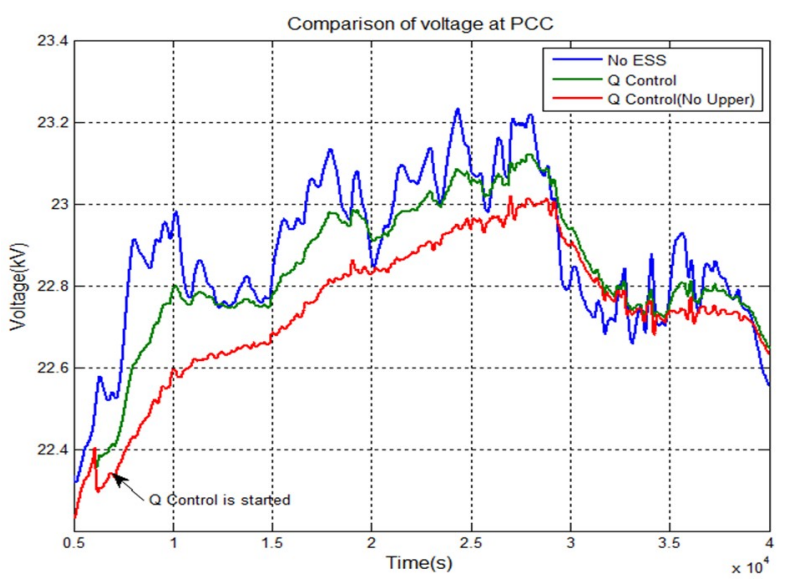

Fig. 20. Mitigation effect of voltage fluctuation according to voltage error compensator (upper compensation)

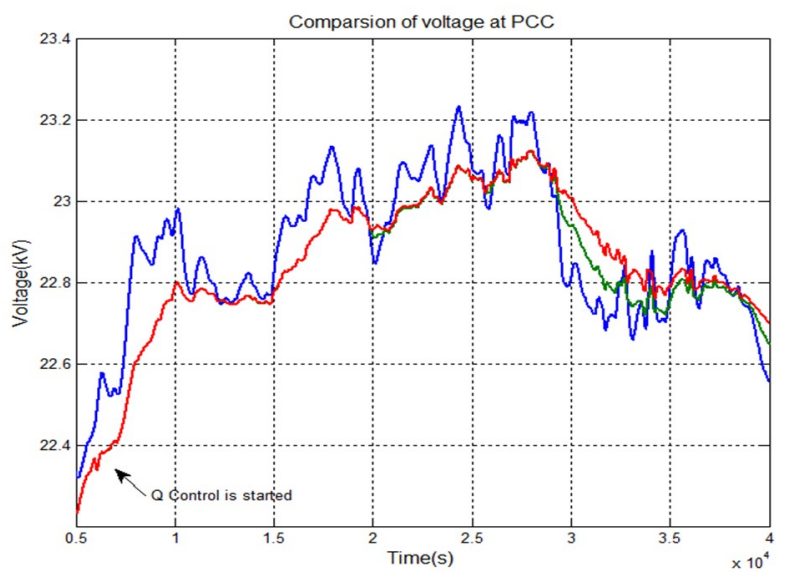

Fig. 21. Mitigation effect of voltage fluctuation according to voltage error compensator (lower compensation) 


\section{Conclusion}

In power smoothing techniques, the method of LPF has a trade-off between damping effect and phase delay. Moreover, it has little effect on the voltage fluctuation in distribution system because of focusing on the active power based on MPPT and PLL. To overcome these demerits, the method of active and reactive power control is proposed in this paper. The performance of proposed power control method is verified through the simulation results such as required active power, elimination of phase delay, and voltage mitigation effect. However, the SOC and SOD is not considered in this paper. Actually, the level of power smoothing effect depends on the SOC and SOD. It means that these factors make a decision on how to constantly perform power smoothing control. Also, environmental factors of wind velocity and irradiation always change. It implies that the frequency component of active power of RES is continuously changing. Therefore, situational adjustment of parameters is necessary for competent power smoothing techniques. Consequently, for the long-term management of power quality in distribution system, these parameters mentioned in this paper should be determined with prudence accordingly.

The larger ESS capacity for power smoothing effect is, the greater the cost is. Therefore, it is very important how the break-even-point between power smoothing effect and ESS capacity is decided reasonably. Therefore, by using our proposed method and algorithm, RES operators can determine the cost-effective capacity of ESS for their benefit.

\section{Acknowledgments}

This work was supported by the Korea Institute of Energy Technology Evaluation and Planning (KETEP) and the Ministry of Trade, Industry \& Energy (MOTIE) of the Republic of Korea (No. 20161210200310).

\section{References}

[1] Renewables 2014 Global Status Report, Renewable Energy Policy Network for the 21st Century, 2014.

[2] R. Teodorescu et al, "Grid Converters for Photovoltaic and Wind Power Systems," New York: John Wiley \& Sons, 2011.

[3] M. A. Mahmud et al, "Voltage Control of Distribution Networks with Distributed Generation using Reactive Power Compensation," IECON 2011-37th Annual Conf. on IEEE Industrial Electronics Society. Nov. 2011.
[4] Wei Li et al, "Wind Power Impact on System Frequency Deviation and an ESS based Power Filtering Algorithm Solution," 2006 IEEE PES Power Systems Conference and Exposition, Oct. 2006.

[5] G. Koshimizu et al, "Subaru Project: Application of Energy Storage for Stabilization of Wind Power in Power Systems," ESA 2005 Annual meeting Conf. Energy Storage Association, Toronto, Canada, 2005.

[6] D. Rastler, "Electricity Energy Storage Technology Options: A White Paper Primer on Apllications, Costs, and Benefits," EPRI, Palo Alto, CA, Tech Rep. 1020676, Dec. 2010.

[7] Sercan Teleke et al, "Control Strategies for Battery Energy Storage for Wind Farm Dispatching," IEEE Trans. Energy Convers., vol. 24, no. 3, pp. 725-732. Sep. 2009.

[8] K. Yoshimoto et al, "New Control Method for Regulating State-of-Charge of a Battery in Hybrid Wind Power/Battery Energy Storage System," IEEE PES Power Systems Conf., vol. 24, no. 3, pp. 725-732. Oct. 2006.

[9] Pedro M. S. Carvalho et al, "Distributed Reactive Power Generation Control for Voltage Rise Mitigation in Distribution Networks," IEEE Trans. Power Systems, vol. 23, no. 2, pp. 766-772, May 2008.

[10] Joan Rocabert et al, "Control of Power Converters in AC microgrids," IEEE Trans. Power Electron, vol. 27, no. 11, pp. 4734-4749, November. 2012.

[11] Zumbahlen, H. "Phase Relations in Active Filters." Analog Dialogue. vol. 41, no. 4. Oct. 2007.

[12] C.L. Nguyen et al, “An Effective Dispatching Power Control to Minimize Energy Storage System in Wind Farm," International Smart Grid Conference \& Exhibition 2013, pp. 600-606, July. 2013.

[13] Li. X., "Fuzzy Adaptive Kalman Filter for Wind Power Output Smoothing with Battery Energy Storage System," IET Renewable Power Generation, vol. 6, no. 5, pp. 340-347, March 2012.

[14] S. S. Cho, "Active Voltage Control \& Field Demonstration for Distribution System with DGs", International Smart Grid Conference 2015, Gwangju, Korea, Oct. 2015.

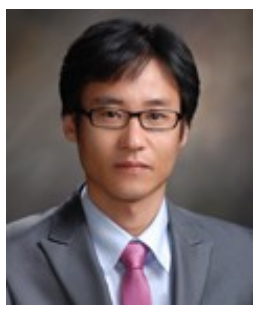

Seong-Su Shin He received the B.S. and M.S. degree in Electric Engineering from Chungbuk National University, Korea, in 2004 and 2007 respectively. $\mathrm{He}$ is currently working toward his $\mathrm{Ph}$. D. in Electrical Engineering at Chungbuk National University. His research interests include operation and design of power distribution systems with distributed generation. 


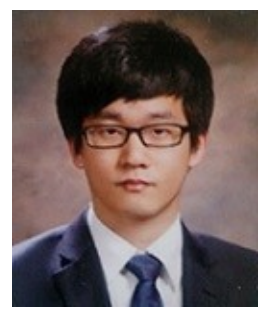

Joon-Seok Oh He received the B.S. and M.S. degree in Electric Engineering from Chungbuk National University, Korea, in 2014 and 2016, respectivley. $\mathrm{He}$ is a manager of distribution planning team in Korea Electric Power Corporation (KEPCO) since 2016. His research activity is focused on the control design of distributed generation, and standard investigation of interconnecting distributed resources with electric power systems.

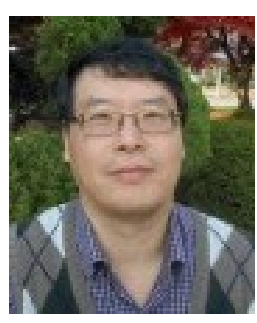

Su-Hyeong Jang He received his B.S. and M.S. degrees in Electrical Engineering from Hanyang Univ., in 1991 and 1994, respectively. He is presently pursuing toward his Ph.D. degree at Chungbuk National Univ. Since 1994, He has been with the R\&D Lab., LS Industrial Systems, is currently a principle research engineer. His research interests include protective relay, WAMS based by PMU, Distributed Generation and Electro Magnetic Compatibility of IED.

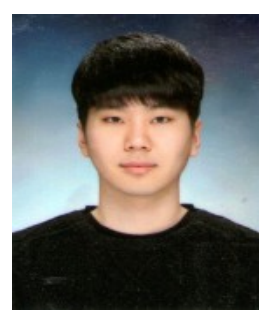

Jae-Hun Cha He received the B.S. degree in Electric Engineering from Chungbuk National University, Korea, in 2016. He is currently working toward his M.S. in Electrical Engineering at Chungbuk National University. His research interests include operation and design of $\mathrm{AC}$ and $\mathrm{DC}$ power distribution systems with distributed generation.

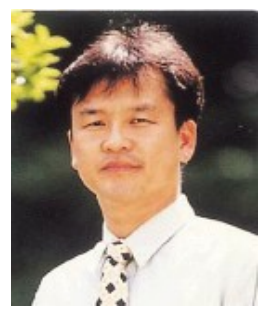

Jae-Eon Kim He received the B.S. and M.S. degrees from the University of Hanyang in 1982 and 1984, respectively. He was affiliated with KERI as a researcher from 1984 to 1989; a senior researcher form 1989 to 1996; and a team leader of advanced distribution systems and custom power lab from 1997 to 1998. He received his Ph.D. from Kyoto University, Japan in 1996. He has been a professor at Chungbuk National University since 1998. His current interests are analysis of power quality; operation and design of power distribution systems with distributed generation and advanced distribution systems, such as micro-grid or smart grid. 